\title{
El Pacto Global como respuesta a la crisis ${ }^{1}$
}

\section{Global Compact as a response to the crisis}

\section{Nuria Inés Giniger ${ }^{2}$}

Resumen: Con las reformas de mediados de los 70, comienza la transformación de la correlación de fuerzas internacional, que derivó en un proceso político, económico y social conocido bajo el nombre de neoliberalismo. Estas políticas tuvieron como consecuencia aumentos del desempleo y la pauperización mundial. Sin embargo, la crisis de esta estrategia no se hizo esperar y los pueblos del mundo resistieron de distintas formas el despojo que se desarrollaba.

El proceso de crisis abierto a comienzos del siglo implica una escala global y civilizatoria. En América Latina, la acumulación de experiencias de resistencia popular, que abordaba diferentes problemáticas, se profundiza con la construcción de alternativas políticas. Los sectores dominantes se vieron obligados a rediseñar una estrategia que recupere la ofensiva, aplaque el descontento y la disputa.

Este proceso tiene dos aristas orgánicas: la reconfiguración del consenso y la avanzada represiva. En este trabajo intentaremos aportar al análisis acerca del Pacto Global como una de las estrategias hegemónicas internacionales para enfrentar la crisis, a través del estudio de fuentes y documentos producidos por la Organización de Naciones Unidas y sus agencias, así como del proceso de trabajo de campo desarrollado por la autora.

Palabras claves: Hegemonía; Pacto Global; Responsabilidad Social Empresaria; Estrategia cultural; Organización de Naciones Unidas

Abstract: With the reforms of the mid-70s began a transformation of the international correlation of forces, which led to an economic, political and social process known as Neoliberalism. These policies resulted in unemployment and global impoverishment. However, the crisis of this imperialist strategy was swift and people resisted dispossession in various ways.

The crisis process inaugurated at the beginning of the century has global implications and a civilizing scale. In Latin America, the accumulation of popular resistance experiences, which addressed different issues, developed with the construction of political alternatives. Dominant sectors, thus, were forced to redesign the strategy so as to regain the offensive as well as to placate discontent and dispute.

This process has two organic axes: the reconfiguration of consensus and the repressive movement. This paper attempts to analyze the Global Compact as one of the international hegemonic strategies to face the crisis, through the study of sources and documents produced by the United Nations and its agencies, as well as through the fieldwork carried out by the Author.

Key words: Hegemony; Global Compact; Social Corporate Responsibility; Cultural strategy; United Nations

1 Recibido: 30/09/16. Aceptado: 10/10/17.

2 Doctora en Antropología. Investigadora Adjunta de CONICET, con sede en Centro de Estudios e Investigaciones Laborales (CEIL-CONICET). Docente de la Universidad de Buenos Aires. 


\section{Introducción: Por qué el Pacto Global}

La configuración del mundo bipolar y de la Guerra Fría, con posterioridad a la Segunda Guerra Mundial, implicó el auge de políticas reformistas, sostenidas en el desarrollo de las fuerzas productivas de la reconstrucción europea y la carrera armamentística, como forma de contrarrestar la presencia del socialismo en la URSS y del llamado bloque del Este, e imprimirle un rostro más democrático y humano al capitalismo occidental.

Este proceso se acompañó con el desplazamiento del epicentro de las luchas de liberación a los países del Tercer Mundo, enfrentando al colonialismo y al imperialismo de diversas formas y con diferentes alcances políticos de dichos procesos. La Revolución Cubana, la victoria vietnamita, los procesos de descolonización de Asia y África, instalaron un "espíritu de época" en los pueblos del Tercer Mundo, que los ubicaba como protagonistas de las luchas antiimperialistas y anticapitalistas. En América Latina, el proceso de acumulación de fuerzas populares, con variados esfuerzos y estrategias de movimientos populares y de izquierda, pusieron al socialismo como esperanza, expectativa y posibilidad de construcción de una sociedad justa.

Hacia la década del 70, las condiciones de posibilidad económicas y políticas del reformismo entran en crisis y se desencadena una nueva ofensiva del capital. Para nuestro continente, se impuso aquello que Perry Anderson (1988) denominaba como contrarrevolución preventiva, que vendría a frenar y destruir el avance popular, a través del Terrorismo de Estado y el genocidio. La doctrina imperialista impulsada por el gobierno estadounidense de Lyndon Johnson (1963-1969), y continuada por sus sucesores, definía destruir a como dé lugar la resistencia popular bajo la Doctrina de Seguridad Nacional, que instruía a las fuerzas armadas a poner en juego toda su capacidad represiva contra los pueblos en lucha.

Como plantea Regalado,

en virtud de la violencia contrarrevolucionaria ejercida por el imperialismo norteamericano y sus aliados en la región, de las debilidades y errores de las fuerzas populares, y del cambio en la correlación mundial de fuerzas que se produciría con el desmoronamiento del bloque socialista europeo y de la propia Unión Soviética, en América Latina y el Caribe fueron destruidos todos los procesos de orientación popular, tanto de carácter revolucionario como reformista, que comenzaron con posterioridad al triunfo de la Revolución Cubana (2008: 18).

Así comienza un proceso de ofensiva económica, política, ideológica y cultural contra los pueblos, conocida bajo el nombre de neoliberalismo, que se profundiza con el fin de las dictaduras militares y la implantación de una estrategia "democrática" burguesa, con elecciones libres y regulares, bajo la tutela de los organismos internacionales de crédito a través de la deuda externa, garantizando la impunidad y por tanto, la inmediata represión a los movimientos de protesta. De esta forma, la estrategia imperialista para América Latina consistió en establecer la "democracia" representativa como único esquema posible ${ }^{3}$, la apertura al libre comercio y el aumento de la presencia militar, a través de la proliferación de bases militares estadounidenses. 
Las reformas neoliberales, sostenidas bajo el Consenso de Washington y el Plan Brady, tuvieron como consecuencia, entre otras, la privatización de empresas estatales y los aumentos escalofriantes del desempleo y la pauperización. Como describe Harvey,

la empresarialización, la mercantilización y la privatización de los activos previamente públicos ha sido un rasgo distintivo del proyecto neoliberal (...) se han privatizado, en mayor o menor grado, toda clase de servicios públicos (el suministro de agua, las telecomunicaciones, el transporte), el sistema de provisión social gestionada por el Estado del bienestar (viviendas sociales, educación, asistencia sanitaria, el sistema de pensiones), instituciones públicas (universidades, laboratorios de investigación, prisiones) e, incluso, todas las competencias relativas a la guerra (como ilustra el "ejército» de contratistas privados que opera junto a las fuerzas armadas en Iraq) (2007: 167).

Sin embargo, la crisis de esta estrategia imperialista no se hizo esperar. La cantidad de desempleados creció exponencialmente, junto con la pobreza, la destrucción de los sistemas de salud y educación públicos, la falta de acceso a la vivienda, a la cultura y ni que hablar al ocio ${ }^{4}$. Este escenario produjo en Europa el recrudecimiento de la xenofobia, de los conflictos étnicos y de la violencia reaccionaria. En América Latina, las luchas contra el neoliberalismo tomaron formas y alcances diferenciados, pero sin duda los pueblos latinoamericanos buscaron su manera de resistir a semejante despojo. Desde la propuesta zapatista mexicana, hasta las articulaciones políticas populares de Brasil y Uruguay, junto con las luchas por reivindicaciones específicas que se fueron desplegando a largo y ancho del continente, fue poniéndose en jaque la hegemonía absoluta del neoliberalismo en la región, con la referencia de la supervivencia de la Revolución Cubana ${ }^{5}$.

Hacia fines del milenio, la acumulación de experiencias de resistencia popular era variopinta y abordaba diferentes problemáticas: la victoria de Chávez en Venezuela, las luchas de los movimientos anti-globalización (de las luchas en Seattle a agrupamientos como Attac), de los movimientos por la tierra y la agricultura familiar y comunitaria (desde los Movimientos Sin Tierra y Vía Campesina hasta las ONGs ecologistas), las inmensas luchas de trabajadores desocupados y de aquellos organizados sindicalmente, las de las mujeres y la creciente visibilización de las problemáticas vinculadas a los géneros, la lucha contra la impunidad de los movimientos de derechos humanos, entre otras. Estas luchas tuvieron (y tienen) perspectivas políticas diferentes. Algunas de ellas se articulan o

significado la dictadura, la democracia era vida. Como plantea Wanschelbaum (2014), de esta forma, legitimaba la democracia representativa, republicana y liberal como la única forma posible de existencia humana.

4 Hacia 1993, en el Tercer Mundo había 1200 millones de pobres, 786 millones con desnutrición crónica, 180 millones de niños gravemente desnutridos, 1500 millones de personas sin atención médica, 1000 millones de analfabetos, 270 millones de mujeres, entre 19 y 49 años, anémicas (Fuente: Foro de San Pablo, 1993).

5 Este proceso complejo de debates y estrategias diferenciadas del movimiento popular y la izquierda está muy bien explicado por Regalado (2007). Aunque no es motivo de este artículo, estas diferencias constituyen un nudo central para comprender la configuración del Pacto Global como estrategia hegemónica, en el sentido que muchos movimientos populares se incorporaron y sostienen entusiastamente las políticas de RSE. 
articularon con proyectos emancipatorios, pero la inmensa mayoría se encontraba dispersa y dividida.

Luego del 11 de septiembre de 2001, con la caída de las Torres Gemelas, recrudece la ofensiva represiva y -a pesar de la fuerte oposición internacional- Estados Unidos invade Iraq. Pero el desafío que el pueblo iraquí le presenta a los invasores impidió que aquello se convirtiera en elemento ejemplificador/disciplinador y las luchas se mantuvieron, en algunos casos aún más radicalizadas.

El proceso de crisis abierto a comienzos del siglo y con las eclosiones financieras de 2008 y 2009, plantean entonces una crisis de escala global y civilizatoria ${ }^{6}$.

En este marco, en América Latina, se profundiza la construcción de alternativas políticas, con variada intensidad, que en sus versiones radicalizadas encuentra a los procesos de Venezuela, Bolivia y Ecuador, al menos, poniendo en discusión el contenido de clase de la lucha por los derechos humanos, por la tierra, por la vivienda, por la salud y por la educación. Esto implicó un salto cualitativo, que abrió nuevos debates en el seno de los movimientos populares, sobre todo respecto al alcance de las transformaciones. Es en este proceso que los sectores dominantes -sufriendo tensiones y embates- se vieron obligados a rediseñar una estrategia que recupere la ofensiva, aplaque el descontento y limite la disputa, incorporando e incluso teniendo en consideración para la negociación a sectores del movimiento popular ${ }^{7}$.

Este proceso de recuperar la iniciativa, tiene dos aristas orgánicas y por tanto complementarias: la reconfiguración del consenso y la avanzada represiva. Respecto de esta última, los golpes institucionales intentados (y como en el caso de Honduras y Paraguay, logrados) por las fuerzas policiales, conjuntamente con la promulgación de legislaciones llamadas antiterroristas, fueron las estrategias imperialistas represivas más difundidas en América Latina ${ }^{8}$.

En este trabajo, intentaremos aportar al análisis acerca de la construcción de la estrategia hegemónica, específicamente en lo que respecta a la propuesta ideológica/cultural del imperialismo para enfrentar la crisis. La noción de estrategia hegemónica la elaboramos a partir del concepto de hegemonía desarrollado por Antonio Gramsci (1992), como el proceso de dirección ético-político del grupo social fundamental sobre el conjunto de la sociedad. En el proceso de hegemonía, la tarea de cosificar la explotación y por tanto, hacer pasar el interés de las clases dominantes por el interés general, invoca los contenidos éticos-morales, propios del sentido común configurado históricamente. Según el propio Gramsci, la hegemonía se produce históricamente, en una relación

6 Llamamos "crisis civilizatoria" a la crisis actual siguiendo a, entre otros, Atilio Borón quien propone que "se trata de una crisis integral de un modelo civilizatorio que es insostenible económicamente; políticamente, sin apelar cada vez más a la violencia en contra de los pueblos; insustentable también ecológicamente, dada la destrucción, en algunos casos irreversible, del medio ambiente; e insostenible socialmente, porque degrada la condición humana hasta límites inimaginables y destruye la trama misma de la vida social" (2009: 1).

7 Aunque no se trata aquí de categorizar este proceso de incorporación-negociación el movimiento popular, vale la pena recordar que Gramsci (1992) plantea estos procesos modernos como fenómenos cesaristas. En todo caso, sí es necesario subrayar que en el proceso de consolidación del Pacto Global y en las políticas de Responsabilidad Social Empresaria participan activamente sectores populares, disputando, negociando e incorporándose a iniciativas concretas.

8 En otras latitudes, las invasiones siguen a la orden del día, como en Siria, Ucrania, etc. 
dialéctica entre consenso y coerción. De esta forma, las disputas ideológicas y culturales, que se expresan en instituciones de distintos niveles, son centrales en la producción de consensos ${ }^{9}$.

En este sentido, y es el propio Gramsci quien lo indica, en los procesos de crisis, retomar la iniciativa por parte de las clases dominantes y recuperar, cooptar y contener la conflictividad social, es central en la configuración de la estrategia hegemónica.

El propósito de este artículo es analizar el Pacto Global (PG) como una herramienta impulsada por Naciones Unidas, que tiene la intención de hacer confluir actores centrales del concierto mundial (empresas transnacionales, organizaciones internacionales, gubernamentales y no-gubernamentales, sindicatos, movimientos sociales, etc.) en una misma política compleja, con pretensiones totalizadoras. Algunos sectores del movimiento popular han dado su visto bueno y participan activamente del Pacto Global o de iniciativas parciales del PG o de Responsabilidad Social Empresaria. Estos sectores negocian y disputan en este terreno, con concepciones diferentes y muchas veces antagónicas al neoliberalismo. Sin embargo, el propósito de este trabajo no es analizar la participación de estos movimientos y organizaciones populares en el Pacto Global, sino comprender cómo éste incorpora reivindicaciones arraigadas en las clases subalternas para configurar una propuesta que (re)legitime al capitalismo actual. En este sentido, aunque el Pacto Global, como cualquier fenómeno social, debe ser abordado de forma conflictual y dinámica en la historia, estudiaremos aquí cuál es la condensación de este proceso en una propuesta novedosa y homogénea impulsada por Naciones Unidas.

Para ello, hemos desplegado una estrategia metodológica cualitativa, de abordaje en profundidad, en la cual combinamos fuentes de distinto tipo. Por un lado, hemos producido fuentes primarias, a través de un proceso de inmersión en el campo empírico de la Red Local del Pacto Global, en Argentina. Abordamos este trabajo de campo con múltiples técnicas: entrevistas en profundidad, observación participante, observación noparticipante, etc. Los registros de dicho trabajo (incluidas notas de campo y fotografías) han sido analizados a través de matrices de datos simples y cruzadas.

Por otro lado, realizamos una búsqueda orientada de fuentes secundarias: documentos y materiales producidos por los actores que participan y forman parte del Pacto Global. Estas fuentes abordan distintos niveles de análisis y para este artículo hemos seleccionado el análisis de las más pertinentes.

La estrategia metodológica inductiva elegida nos ha permitido construir una periodización, determinados nodos problemáticos que articulan lo que llamamos la matriz ideológica-conceptual del Pacto Global e identificar los elementos que se articulan en dicha matriz y constituyen el corazón de las concesiones e incorporaciones de reivindicaciones populares. Luego, hemos encontrado una forma de expresar este análisis que incorpora elementos de ilustración o ejemplificación. Estos elementos pretenden simplemente ayudar a comprender la concreción de las políticas estudiadas.

\footnotetext{
9De esto deviene la importancia que Antonio Gramsci le otorgaba al estudio de las políticas y a las instituciones como la Iglesia, la escuela, la literatura de folletín, etc, así como al rol de los intelectuales como conductores de esos procesos políticos. Los consensos implican negociaciones, disputas, compromisos, concesiones. Sin embargo, a pesar de las lecturas de Gramsci como "intelectual del consenso", el italiano jamás le restó peso a la coerción. Por el contrario, estableció la dialéctica entre ambos, recuperando, aún en el régimen fascista (coercitivo de por sí), el lugar de la disputa ideológica y cultural.
} 
El Pacto Global, como planteamos, tiene una pretensión "universal" y por tanto, mundial. Sin embargo, como veremos en el desarrollo de este trabajo, se especializa en contextos situados. Es por ello que aquí presentamos el análisis general de la política impulsada por Naciones Unidas, así como la forma específica que adquiere en la Argentina y en una empresa transnacional emplazada, entre otros lugares, en este país. En Argentina hay una importante difusión y acción específica de las prácticas del PG, entre el empresariado, e incluso tiene prácticas institucionalizadas desde hace una década. Es por ello que consideramos un caso interesante para analizar cómo se despliega en el nivel mundial y en el nivel local el Pacto Global.

\section{El Pacto global como parte de la estrategia hegemónica}

Frente a la crisis global y a la fuerza de las reivindicaciones populares, los sectores dominantes configuran una propuesta de salida a la crisis, con pretensiones de reconfiguración hegemónica. Como planteamos en otra oportunidad (Giniger, 2014), es de largo aliento la intensión y los esfuerzos por pintarle un "rostro humano" al capitalismo neoliberal. Uno de los actores que mayor preeminencia tuvieron en la pretendida "humanización" del capitalismo neoliberal fue la Iglesia Católica, con las encíclicas de Juan Pablo II. La noción de que el Estado es obstáculo de desarrollo y que al trabajador hay que considerarlo como "el prójimo", y por tanto plausible del "bien común", configura el basamento ético y político de la Responsabilidad Social Empresaria (RSE). Ésta emerge como política de lavado de cara de las empresas, simultáneamente al neoliberalismo. Sin embargo, también dimos cuenta de que durante el auge de la implementación del neoliberalismo, a principios de la década del 90 , con las doctrinas de management participativo ${ }^{10}$ y la teoría del derrame, la difusión y desarrollo de la Responsabilidad Social Empresaria se estancó (Giniger, 2014).

Durante la década del 90, hay antecedentes explícitos que anticipan la concreción del Pacto Global, en la ONU. Uno de ellos es el Informe del Secretario General "Desarrollo y Cooperación económica internacional. Un programa de Desarrollo", del 6 de mayo de 1994. En su punto 148, dice lo siguiente:

Las inversiones internacionales privadas han llegado a 1 billón de dólares por año y ofrecen inmensas posibilidades de creación de empleos, transferencia de tecnología, capacitación y promoción del comercio. El dinamismo librado en este proceso puede revivir las economías estancadas y promover la integración en el sistema económico mundial. La inversión extrajera directa puede tener un efecto positivo al poner una serie de recursos tecnológicos a disposición de los países para su desarrollo. La empresa privada se considera cada vez más un factor positivo en la solución de los problemas que antes se suponían de la jurisdicción exclusiva de las autoridades públicas... (p. 29) 
Este informe, además de impulsar explícitamente la privatización de los servicios públicos, ubica a las empresas privadas como factores de dinamismo y de desarrollo, como un actor capaz de solucionar problemas que antes resolvía el Estado.

Asimismo, en el Informe de la Cumbre Mundial sobre Desarrollo Social, de Copenhague, en 1995, se postulaba en la misma dirección:

Pero, en este proyecto social nuestro, será necesario tener en cuenta también la extraordinaria capacidad de movilización de las organizaciones no gubernamentales y la facultad de integración que ofrecen la empresa privada y los inversionistas (...) Al elevar la cuestión social al rango de las prioridades universales, queremos tomar las riendas del destino colectivo de la sociedad internacional y concluir un nuevo pacto de solidaridad a escala del planeta. (p. 143 y144)

Nuevamente, se apela a las empresas privadas como actores centrales del proyecto social de la ONU (junto con las ONGs) y luego, a la construcción de un "nuevo pacto" en el marco de los programas de desarrollo. Estos antecedentes van configurando la legitimación del rol de las empresas en los propósitos de la ONU y su participación activa y directa se despliega en la medida en que se concreta el Pacto Global, a partir de 1999.

Es recién en el marco de la crisis, a principios de este siglo, que la RSE retoma impulso y comienza un proceso de sistematización política, cultural e ideológica. Este proceso tiene un hito importante el 31 de enero de 1999, cuando quien fuera secretario general de Naciones Unidas en aquel momento, Kofi Annan, dio un discurso en el Foro Mundial Económico de Davos, donde postulaba la iniciativa denominada Pacto Global ${ }^{11}$ :

Este año, quiero desafiarlos a unírseme en llevar nuestra relación a un estadio superior. Les propongo que ustedes, los dirigentes empresariales reunidos en Davos, y nosotros, la Organización de Naciones Unidas, iniciemos un pacto global de valores y principios compartidos, que le otorguen un rostro humano al mercado mundial12.

La propuesta del Pacto Global, en 1999, recién comenzaba a sintetizar elementos de cuestionamiento al capitalismo neoliberal, recuperando demandas populares y articulándolas orgánicamente en un marco ético. La apelación a los valores y principios como sustento de políticas de articulación entre la ONU, los Estados y las empresas no es novedosa13, sino que como planteamos en la introducción, la pretensión de hacer pasar el interés de la clase dominante por el interés del conjunto de la sociedad, invoca contenidos éticos y morales configurados históricamente. En este sentido, los valores y principios a los que apela el Pacto Global son "universales".

Los sentidos éticos que van a desplegarse con la iniciativa del Pacto Global están matrizados bajo tres elementos: el bien común, la sustentabilidad y la responsabilidad. Respecto del primero, su proveniencia desde la teología y de otras teorías configura un sentido muy complejo, que excede las pretensiones de este artículo. Solo queremos señalar que dentro de las teorías de la armonía social, podemos inscribir al bien común

11 En las iniciativas oficiales del Pacto Global en los países de habla hispana, se menciona de esta forma. Sin embargo, en muchos documentos traducidos aparece como Pacto Mundial.

12 Traducción propia del discurso de Kofi Annan en el Foro Mundial Económico, en Davos, Suiza.

13 Para revisar las presiones de las empresas transnacionales ver Vidal, María del Mar (2015) La dimensión internacional de la Responsabilidad Social Empresaria, España, Editorial Bomarzo 
como fuente de normalidad y unicidad de la sociedad. De esta manera, la noción de bien común atraviesa la doctrina de RSE, ya que se invisibilizan los conflictos de clases.

Acerca de la segunda noción, la sustentabilidad, su difusión viene asociada a la RSE, pues está elaborada bajo la premisa de que hace falta diseñar planes a largo plazo, para garantizar el presente, sin poner en riesgo el futuro. Esta perspectiva es central en la RSE, porque plantea un futuro sin los riesgos que el capitalismo nos muestra cotidianamente, tanto a los trabajadores como al medio ambiente, y por lo tanto, se convierte en el núcleo de posibilidad de un capitalismo con rostro humano y ambiental.

La noción de responsabilidad también es clave en el corpus doctrinario. La crítica que sustenta la propuesta de la RSE y el Pacto Global es la idea de que el capitalismo hasta ahora ha sido cortoplacista e irresponsable, nos ha dejado un presente conflictivo y contaminado y, por tanto, no ha cumplido con la idea de que el desarrollo (capitalista) trae beneficios para toda la humanidad. Es así que la propuesta actual plantea la necesidad de ser responsables. En este sentido, Delgado (2007) es muy explícito cuando sostiene que se le agrega "socialmente responsable" para lavarle la cara a ideas que implican mayor explotación y acumulación de capital.

En el inicio de la crisis, el secretario general de Naciones Unidad impulsa la articulación de las corporaciones transnacionales, los Estados y los organismos internacionales para configurar una política totalizante de capitalismo con rostro humano. Se trata de reponer la expectativa de que el capitalismo es mejorable, es la sociedad que nos tocó y que va a traer, finalmente, bienestar al conjunto del planeta.

Los países industrializados aprendieron la lección con el amargo y costoso encontronazo con la Gran Depresión. En orden a restablecer la armonía social y la estabilidad política, ellos adoptaron redes de seguridad sociales y otras medidas, destinadas a limitar la volatilidad de la economía y compensar a las víctimas de las fallas del mercado (...) Nuestro desafío hoy es construir un acuerdo similar a escala global, que sostenga la nueva economía mundial. Si somos exitosos, sentaremos las bases de una época de prosperidad global, comparable con aquellas que disfrutaron los países industrializados décadas después de la Segunda Guerra Mundial. Los convoco -individualmente a través de sus compañías y colectivamente a través de sus asociaciones empresariales- a abrazar, apoyar y poner en práctica un conjunto de valores nodales en las áreas de derechos humanos, estándares laborales y prácticas medioambientales ${ }^{14}$.

El Pacto Global incorpora de esta forma reivindicaciones populares y sujetos/organizaciones populares: los que luchan por los derechos humanos, los que luchan por mejor y más trabajo, los que luchan por la protección del hábitat, etc. Sin embargo, el contenido de la lucha se enmarca en los límites del capitalismo. El trabajo debe ser decente; el medioambiente, limpio y sustentable; los derechos humanos, aquello que dice la norma escrita. De esta forma, se instalan los límites de lo posible: se trata de aquellos consensos que hemos configurado a lo largo del último siglo y que se han plasmado en instituciones internacionales, como la Organización Internacional del Trabajo, la Declara-

14 Traducción propia del discurso de Kofi Annan en el Foro Mundial Económico, en Davos, Suiza. 
ción de Derechos Humanos de la ONU, la Cumbre de Rio y otras, y que no ponen en cuestión el status quo, ni plantean una salida anticapitalista a la crisis.

Los principios del Pacto Global, entonces, pretenden contener y englobar estas reivindicaciones populares y organizarlas bajo la doctrina de Responsabilidad Social Empresaria:

Respecto a los Derechos Humanos, se postula que las empresas deben respetar los derechos proclamados como tales en las Declaraciones internacionales y no ser cómplices de abusos.

Acerca del Trabajo, las empresas deben respetar la libertad de asociación y la negociación colectiva, así como promover la eliminación de trabajo forzoso e infantil y la discriminación.

Referido al Medioambiente, las empresas deben tener un enfoque preventivo, tener mayor responsabilidad ambiental y desarrollar tecnologías respetuosas con el medioambiente.

Y por último, sobre la Corrupción, las empresas deben trabajar contra el soborno, la extorsión y la corrupción.

Esta versión actual del contrato social ${ }^{15}$ tiene pretensión totalizadora e "incluye a todos y todas"; mientras que en la versión roussoniana, "nosotros, los ciudadanos" no incluía ni a los negros, ni a los esclavos, ni a los indígenas, ni a las mujeres... solo a los hombres blancos. En esta estrategia hegemónica renovada, no hay "otros"; todos somos plausibles de inclusión, todos podemos vender y comprar fuerza de trabajo ${ }^{16}$ y de esta forma, articularnos en una red de inclusión mutua. La formulación es que "todos somos stakeholders" de alguna empresa y por tanto, ciudadanos corporativos: clientes, vendedores, accionistas, trabajadores, proveedores, comunidades y consumidores ${ }^{17}$.

Con la profundización de la crisis y el estallido financiero de $2008 / 2009$, el Pacto Global es relanzado en Davos. El candidato a reponerlo en agenda es el secretario general de la ONU, Ban Ki-moon, en su discurso "El Pacto Mundial y la creación de mercados sostenibles", el 29 de enero de 2009. Allí plantea algunos elementos centrales tales como que es un "año de múltiples crisis", que las "economías tienen problemas", que "el cambio climático amenaza todos nuestros objetivos de desarrollo y progreso" y que éste es una "amenaza existencial verdadera contra el planeta". Sustenta sus argumentos en que “...encuestas recientes revelan una enorme pérdida de confianza en el mundo empresarial (...) tres de cada cuatro estadounidenses confían menos en las empresas que hace un año. Tan solo un tercio de ellos cree que las empresas actúan de modo correcto (...) Entre los jóvenes, la pérdida de confianza es especialmente notable".

15 Hemos trabajado esta idea en Figari y Giniger, 2014.

16 Esta idea fue muy difundida en el llamado emprendedorismo, durante los 90. Particularmente en Argentina, esta idea fue postulada como alternativa para aquellos y aquellas trabajadores que perdían sus fuentes empleo a partir de las privatizaciones.

17 Es necesario poner énfasis en que estos enfoques acerca del capitalismo más humano y la inclusión como proyecto político son compartidos por importantes (incluso, mayoritarios) sectores y organizaciones populares. Incluso consideramos como hipótesis que es plausible analizar la lucha sindical de las últimas cuatro décadas en esta dirección. No es materia de este artículo el desarrollo de estas cuestiones, pero vale la aclaración para identificar la voluntad más o menos explícita de sectores populares con estos enfoques. 
La respuesta de Ban Ki-Moon a la crisis es entonces profundizar la estrategia del Pacto Global: "si abordamos frente a frente el cambio climático podremos resolver muchos de nuestros problemas actuales, incluida la amenaza de una recesión mundial". Y a esto le agrega, buscar "la cara humana del mercado mundial".

Ban Ki-Moon plantea explícitamente que frente a la imposibilidad del capitalismo global de resolver la vida del planeta, "el Pacto Mundial fue nuestra respuesta clarividente (...) esos miembros se ocupan de proteger el medio ambiente y luchar contra la corrupción. Han llevado a cabo centenares de proyectos en materia de salud, educación e infraestructura en países de todo el mundo". Y agrega lo siguiente: "Nuestro tiempo exige una nueva definición de liderazgo mundial. Exige una nueva constelación en la cooperación internacional: gobiernos, sociedad civil y sector privado trabajando juntos en pro de un bien colectivo mundial (...) Con los problemas actuales de contracción económica y cambio climático, nunca ha habido tanto en juego para las empresas".

Así, el Secretario General de la ONU postula entonces la propuesta: "sin confianza, no habrá prosperidad". El Pacto Global tiene por objeto recuperar la confianza en las empresas, que la célula misma de la organización capitalista recupere su legitimidad. Para Ban es una "oportunidad de oro": "reorientar sus organizaciones y prepararlas para la economía del futuro. A cada contracción le sigue una expansión. Si hacen las inversiones correctas, sentarán las bases para resolver cuestiones fundamentales a largo plazo".

La propuesta es más capitalismo, con rostro humano, sostenido en tecnologías limpias, energías renovables y eficiencia energética. Esto traerá "empleos verdes" y por tanto un futuro sostenible con perspectivas de prosperidad para todos.

Esto se postula como un diagnóstico antagónico al que realizan, entre otros Harvey (2007) y Borón (2009), para quienes la crisis civilizatoria tiene como causas estructurales la crisis de sobreproducción y la de subconsumo, agregando la acelerada financierización de la economía, la irresistible tendencia hacia la incursión en operaciones especulativas y las políticas neoliberales de desregulación y liberalización. Para ellos, las consecuencias de esto son: el desempleo, la pauperización y un retroceso sistemático en el acceso a los derechos económicos, sociales y culturales y a los derechos civiles y políticos a escala mundial.

\section{El Pacto Global en Argentina}

La audacia del Pacto Global reside en recuperar las iniciativas reivindicativas populares y encolumnarlas bajo la égida de un pacto civilizatorio que retorne la legitimidad y la esperanza al capitalismo. La posibilidad de que con la crisis se re-ponga en discusión la permanencia y garantía del capitalismo para resolver los problemas sociales acuciantes, obliga a las clases dominantes a configurar una renovada perspectiva totalizadora, que vuelva a hacer pasar el interés particular de la burguesía en interés del conjunto de la sociedad, a escala planetaria. La sofisticación que implica el Pacto Global se entiende en América Latina, y especialmente en el Cono Sur, al calor de las luchas populares y del crecimiento de alternativas políticas al capitalismo, como el proyecto bolivariano impulsado por los países del ALBA.

En esta contienda, bien común, sustentabilidad (desarrollo) y responsabilidad son conceptos en disputa en la región. En Argentina, la ofensiva por contener el "desborde" de las reivindicaciones se organiza desde el Estado y la Sociedad Civil con gran audacia. Esta estrategia hace emerger al Pacto Global, pero mayormente a múltiples y variadas 
iniciativas de Responsabilidad Social Empresaria, que pretenden configurar una imagen más amigable, amable y colaborativa de las empresas, luego del derrumbe de la confianza y de la profunda crisis de gobernabilidad de 2001. La posibilidad de restablecer un marco de legitimidad de los negocios en Argentina se imbrica con la premisa de que hay capital bueno y capital malo: están los especuladores buitres y los capitalistas industriales, que invierten y dan trabajo. Sin embargo, las causas del trabajo en negro, precario, son estructurales y poco tienen que ver con los buenos que dan empleo y están dispuestos a aportar al bien común (Giniger, en prensa). La idea de que "si a las empresas les va bien, les va bien a todos", se complejiza con la incorporación de las problemáticas y reivindicaciones configuradas por los pueblos del mundo en su lucha contra la depredación y la mercantilización.

En este sentido, la iniciativa del PG tiene bastante eco entre la comunidad empresarial en Argentina y es un ejemplo interesante para problematizar las respuestas ideológico-culturales a la crisis.

El Pacto Global, junto con el Programa de Naciones Unidad para el Desarrollo (PNUD), impulsa redes locales en los países miembros. En Argentina, la Red Local está bastante extendida y en diciembre de 2013, contaba con 512 empresas y organizaciones en general adheridas, de las cuales 364 permanecen en la actualidad activas y 148 están inactivas ${ }^{18}$.

La Red Local desarrolla iniciativas de difusión y propaganda, que también se articulan con el Estado.

A nivel nacional, existen programas ministeriales que son promovidos junto con la Red Local. Algunas de ellas son:

1. Ministerio de Trabajo, Empleo y Seguridad Social: Red Trabajo Decente y Responsabilidad Social Empresaria

2. Ministerio de Trabajo, Empleo y Seguridad Social: Programa Jóvenes con Futuro

3. Ministerio de Desarrollo Social: Subsecretaría de Responsabilidad Social ${ }^{19}$

Pero como planteamos anteriormente, en la Argentina, la Responsabilidad Social Empresaria se difunde y se despliega, no solo desde el Pacto Global, sino mayormente, a través de fundaciones empresariales, $\mathrm{ONGs}^{20}$, cámaras empresarias y la propia actividad que desarrollan las empresas. Según el Mapeo de Promotores de Responsabilidad Social Empresaria $^{21}$, existen en nuestro país 88 organizaciones promotoras de RSE, cuyas principales líneas de acción son la articulación, el asesoramiento, la capacitación, la divulga-

18 La adhesión al Pacto Global implica que las organizaciones deben presentar anualmente una Comunicación para el Progreso. Aquellas que en el transcurso de dos años no lo hagan permanecen inactivas hasta que lo vuelvan a hacer.

19 El Ministerio de Desarrollo Social articula un programa de RSE para Parques Industriales junto con el Ministerio de Industria.

20 Stella Calloni caracteriza a las fundaciones y ONGs como parte de "un nuevo período de expansión muy peligroso". Según Calloni, estas fundaciones fueron creadas durante la Presidencia de Ronald Reagan en Estados Unidos, para lograr "un rostro social que pretendía ayudar" a los pueblos de América Latina. "Estas fundaciones, a su vez, crean ONGs que muchas veces sin saber trabajan para el enemigo porque en los informes que presenta para justificar el dinero que reciben vuelcan información muy valiosa que permite, por ejemplo, un control de las sociedades y determinar cuál es más factible de colonizar". http://www.entrerios.gov.ar/noticias/nota.php?id=34372

21 http://www.mapeo-rse.info/ 
ción, la estandarización, el financiamiento, la investigación y la organización de premios. Además, podemos agregar, los suplementos dedicados a la temática que salen con diarios de tirada nacional ${ }^{22}$.

Como estrategia hegemónica, el Pacto Global tiene entonces una diversidad de iniciativas que lo configuran y van instalando sentidos y disputando otros. Guiándonos solamente por los datos recién plasmados, podemos inferir que esta multiplicidad de prácticas se orienta a diferentes sectores, en distintas escalas de influencia y por supuesto, con variado éxito.

Analizaremos ahora las conceptualizaciones que movilizaron la creación de la Red Local del Pacto Global, en Argentina, a partir de un balance realizado por los propios protagonistas de su fundación, a diez años de la misma.

\section{Diez años de Red Local en Argentina}

Según los participantes del "Décimo Aniversario de la Red Argentina del Pacto Global" ${ }^{23}$, el PG instala la idea de la Responsabilidad Social Empresaria en el mundo de los negocios "de forma universal". Ni la RSE, ni poner directamente a las corporaciones a participar de los debates, era algo que la ONU realizara anteriormente. Naciones Unidas es una organización de Estados. Sin embargo, como planteó Benigno Rodríguez ${ }^{24}$,

“...el éxito del Pacto Global radica, por un lado, en el poder de convocatoria que ha tenido y que se ha demostrado en un sector, que si bien es clave en términos del desarrollo de los pueblos, no era tradicional para el trabajo de Naciones Unidas; y por el otro, porque ha logrado sentar al mundo corporativo en la mesa de negociación global para discutir los grandes problemas que afectan el desarrollo sostenible" (Rodríguez, 2014: 3).

Es interesante y llamativo el cambio de paradigma que comienza a desplegarse en el Sistema de Naciones Unidas para mediados de la década del 90. El Pacto Global es la institución de la ONU cuyos principales representantes (stakeholders) son empresas, especialmente grandes corporaciones. No significa esto en lo más mínimo que antes de la creación del PG las empresas no participaran del debate del concierto de las Naciones, pero no era de forma directa. La institucionalización de la participación directa de las empresas se realiza con el Pacto Global.

Como señalamos, el PG tiene 10 principios. En el "Décimo Aniversario de la Red Argentina del Pacto Global", se mencionaron estos principios como Universales, en tiempo y espacio. Estos 10 principios se trabajaron en la jornada como apelativos morales, y los valores también se pretenden universales. En este sentido, la configuración de valores, sin distinción de clase, género, etnia, es una base indispensable para indiferenciar las diferencias, y así habilitar la incorporación de sentidos comunes a todos que, como ve-

22 Por ejemplo, los diarios argentinos Tiempo Argentino y el Cronista.

23 Tomamos en este apartado los testimonios del evento citado, con nombre y apellido, ya que se trata de personas públicas y su participación fue difundida por la Red Local.

24 Benigno Rodríguez, Representante Residente PNUD. Fue Representante Residente Adjunto en el PNUD de Venezuela, Uruguay, Chile, Nicaragua, y actualmente en Argentina. 
remos específicamente luego con un caso, retoman reivindicaciones históricas: el derecho a la educación, el derecho al trabajo, el derecho a la integridad, el derecho a la autodeterminación, etc.

El sentido es cohesionar y unir negocios con valores. Para ello, se plantea lo siguiente: “...hay que reconocer la evangelización hecha por el Pacto Global en el mundo de los negocios para que la agenda de sustentabilidad esté realmente presente hoy en la mayoría de las empresas, ese es un gran logro" (Ávila ${ }^{25}, 2014: 5$ ).

Ávila lo plantea de forma muy explícita: evangelizar ${ }^{26}$. Hay que predicar y convencer para construir los consensos y las adhesiones al Pacto Global. Y en esta dirección, la herramienta de fiscalización e introyección son las Comunicaciones de Progreso o Reportes de Sustentabilidad (Figari y Giniger, 2014). Sin embargo, Ávila acá sitúa solo la evangelización al mundo de los negocios. Las herramientas diversificadas de comunicación, difusión y producción de sentidos, que se despliegan desde la Red Local y las propias empresas adherentes, nos hacen reflexionar fundamentalmente acerca de que la evangelización es más allá del empresariado.

Los actores que participaron del lanzamiento del Pacto Global en Argentina, hace 10 años, consideran que esta es una iniciativa digna de ser celebrada. Entre ellos, el lanzamiento del PG en Argentina tiene un halo de "buena voluntad" que lo rodea. Es un grupo de personas, el llamado grupo promotor, con voluntad y desinterés, que se embarca en una aventura: convencer y sensibilizar a distintos organismos (fundaciones, universidades, sindicatos) y empresas (multinacionales y pymes) para que participen y adhieran a una construcción colectiva, bajo el amparo de lo que denominan "Casa Segura": ONUPNUD.

En la "aventura" de la conformación de la Red Local, hay sentidos que no permiten visibilizar ni intereses ni propósitos. Son un grupo de personas que "se la juegan y arman" -asegurados y legitimados por la ONU- la Red Local del PG. La noción "grupo de personas" como grupo promotor, hace desaparecer a las organizaciones y sus intereses.

En el relato acerca de la conformación de la Red Local, no hay propósito manifiesto; hay un proceso de institucionalización por el cual se atraviesa sin fisuras aparentes. Es decir, en este proceso colectivo de creación se configura una red que se institucionaliza a través de la Mesa Directiva Multistakeholders.

Sin embargo, solo con la buena voluntad y desinterés del grupo de personas, no basta. El lugar seguro, es decir la seguridad de que la iniciativa tiene sentido, la otorga la Naciones Unidas, y más específicamente el PNUD. Este paraguas cubre tanto los gastos básicos ${ }^{27}$ (funcionarios, infraestructura), como la legitimación que le otorga la dimensión mundial de la iniciativa.

25 Andrea Ávila: representante de la Red Argentina del Pacto Global; CEO de Randstad Argentina y Uruguay, abogada por la Universidad Católica Argentina, y magister en Asesoramiento Jurídico de Empresas por la Universidad Austral. Es miembro de las comisiones directivas de la Federación Argentina de Empresas de Trabajo Temporario y de la Cámara Argentina de Servicios Empresariales Especializados y Complementarios. Miembro de la Comisión Directiva de MoveRSE.

26 No es casual el apelativo al Evangelio, en otros trabajos hemos desarrollado el vínculo entre la Responsabilidad Social Empresaria y la Doctrina Social de la Iglesia. Ver: Giniger, 2014.

27 La iniciativa del Pacto Global tiene como característica que el financiamiento general debiera estar dado a través de la colaboración voluntaria de empresas. Es un objetivo del director general del PG que no haya presupuesto propio de la ONU, sino que sea autofinanciada con aportes empresariales. Por lo que 
La programática del Pacto Global se asienta en los principios de la Responsabilidad Social Empresaria. Para los participantes del "Décimo Aniversario de la Red Argentina del Pacto Global", hubo que configurar un "entramado inicial de confianza para gestionar en términos de Responsabilidad Social" (Videla, 2014: 1).

Sin embargo, la noción universalista de la RSE y del PG fue puesta en tensión cuando se planteó la implementación de estas políticas a nivel gubernamental. El Ministro de Trabajo, Carlos Tomada, manifestó en el encuentro que la responsabilidad social no es una idea uniforme:

No puede ser lo mismo la Responsabilidad Social en Holanda, que la Responsabilidad Social Empresaria en Bangladesh, y no lo es tampoco en la Argentina. $Y$ un país como la Argentina, donde el trabajo ocupa una centralidad tan grande en los procesos de inclusión, junto con la educación diría yo, son los dos valores históricos que construyeron la inclusión social en la Argentina, no es lo mismo en Holanda que en Bangladesh". La fórmula postulada por el Ministro es "cruzar responsabilidad social con trabajo decente (...) nos iba a dar muy buenos resultados y eso fue lo que ha estado ocurriendo (2014: 2).

Hay un esfuerzo en desplegar la implementación del PG a nivel nacional y local, resituando los "valores universales" en los contextos específicos. Y según los participantes al evento, los resultados de desarrollar una iniciativa integral de RSE en la Argentina ha conducido a un ingreso masivo del empresariado al "movimiento" de RSE: "en la actualidad son pocos los empresarios y empresarias del país que no muestran interés por ello" (Rodríguez, 2014: 1).

La Red Local se estableció en el año 2004. Según los participantes a la celebración de los 10 años, el primer año hubo debates acerca del cuerpo de gobierno de la Red y para ello debieron construir los consensos necesarios tanto con el sector privado como con la "plataforma multistakeholders". Basados en "principios éticos universales" y en el "prestigio de empresas e instituciones" (De Bueno ${ }^{28}, 2014$ ), establecieron un entramado regional y nacional cuya tarea era la búsqueda de adhesiones y la bajada de los principios del PG.

La propuesta organizativa de la Red Local tiene el apoyo del PNUD y "otras agencias hermanas de la ONU", pero los participantes al evento plantearon la necesidad de configurar una "nueva institucionalidad". En esta definición hay dos elementos: por un lado, el enfoque y participantes de la Red, y por otro, la implementación concreta y eficaz de los principios del PG.

Sobre los participantes de la Red, se manifestaron dos preocupaciones: la ausencia de sindicatos en la Mesa Directiva y las dificultades que tienen las Pymes para participar activamente, ya que no cuentan con departamentos específicos y debieran reestructurar las direcciones de las empresas para hacerlo. En la pretensión de que la Mesa Directiva sea efectivamente un espacio multistakeholders, estos dos actores son centrales, ya que ponen en juego la personificación de aquellos a quienes el PG teóricamente vendría a promover. Para los protagonistas la dinámica y el enfoque de la Red implica "combinar flexibilidad, 
capacidad de respuesta y liderazgo empresarial" (Rodríguez, 2014: 2). El liderazgo es evidente, pero requiere de la participación de otros actores para su concreción.

En cuanto a la implementación del PG, se apela a las experiencias particulares, es decir, a los programas de RSE que las empresas ponen en marcha y que comunican a través de sus reportes de sustentabilidad. Pero también, en la actividad hubo una apelación a que se puedan "mostrar las sombras", es decir, las dificultades.

La experiencia de los programas de las empresas en materia de RSE es fundamental para resituar el PG en los territorios y reconvertir las demandas generales en acciones particulares dirigidas por las empresas. "Mostrar las sombras" se hace entonces imprescindible, pues canalizar el conflicto social en programas empresariales implica la sofisticación permanente de los dispositivos puestos en juego. Luego lo veremos, pero adelantamos que recuperar las propias demandas sociales situadas, le otorga efectividad a los propósitos del PG.

Además, en materia de comunicación y apuesta pedagógica general, la Red Local y el Centro Regional organizan una serie de actividades de difusión o productos, como los denominan $^{29}$.

El vínculo entre la puesta en práctica y el contexto económico apareció en el evento con fuerza. El gerente de asuntos sociales de Volkswagen Argentina planteó la necesidad de redoblar los esfuerzos en la implementación de los 10 principios, en contextos de turbulencias económicas. No hacerlo, sería "como cerrar un hospital en un momento cuando tenés una epidemia. Y lamentablemente muchas en el ámbito empresarial funcionan al revés y siempre los baches para actividades sociales son los primeros que están en riesgo cuando hay algunas nubes en el cielo." (Prock, 2014: 3). Este llamamiento a dar por tierra el "cortoplacismo" empresarial, como planteamos anteriormente, es uno de los fundamentos del PG. En Argentina, está muy difundida la idea crítica de que el empresariado es incapaz de proponer planes de mediano y largo alcance ${ }^{30}$, con lo cual, las menciones a revertir esta supuesta tendencia, suelen encontrar eco social.

En el proceso de implementación, se establecen dos momentos: un momento al que llaman "normativo", que es aquel en el cual se difunden las ideas y principios del Pacto Global, y un momento "cultural", cuando se instala el PG dentro del modelo de negocios y "cada persona lo va a tener internamente, entonces ahí va a estar el ciudadano ${ }^{31 "}\left(\right.$ Willi $\left.{ }^{32}, 2014: 1\right)$. El Pacto Global como dimensión de la configuración hegemónica

\footnotetext{
29 Algunas de las iniciativas son: la Cátedra del Pacto Global, que se realiza en distintas universidades; el Programa de Formación de Líderes para el Cambio de la Industria Textil y de la Moda; el Taller "Modelo de Gestión del Pacto Mundial"; y el Foro Empresarial del Pacto Global de América Latina, "que es uno de los productos que hemos creado desde el Centro Regional", expresó Diana Chávez (2014: 3), directora del Centro Regional de apoyo al Pacto Global para América Latina y el Caribe.
}

30 Hemos discutido la idea del cortoplacismo empresarial en trabajos anteriores. Ver Teszkiewicz, Winter, Wanschelbaum, Reboursin, Giniger, 2012.

31 En un trabajo anterior, dimos cuenta de los propósitos de configuración de un ciudadano corporativo y sus implicancias en la política del Pacto Global. Ver Figari y Giniger, 2014.

32 Alberto Willi es Licenciado en Ciencia Política por la Universidad de Buenos Aires y en Filosofía por la Universidad Católica Argentina. Magister en Dirección de Empresas del IAE y doctorando en el School of Management University of Bath. Profesor del área Empresa, Sociedad y Economía y director de la Dirección de Formación Humanística del IAE y la Universidad Austral. Dicta clases en el área de Comportamiento Humano. 
se ancla en estos dos aspectos, el "normativo" y el "cultural", en la medida en que construye sentidos y prácticas que se especializan en contextos específicos, sustentados en una matriz de época que le otorga a las grandes corporaciones un rol preponderante.

A continuación, como adelantamos, consideramos que es importante identificar específicamente cuáles son las iniciativas que las grandes empresas llevan adelante. La influencia de éstas directamente en la elaboración de las políticas está evidenciada en las conferencias de Davos, que antes mencionamos. Pero dicha influencia global tiene su especialización en los ámbitos de influencia de las mismas en los lugares de emplazamiento de sus plantas. Venimos sosteniendo que las políticas empresariales globales y los sistemas corporativos se especializan en los espacios nacionales y locales particulares, atendiendo a la propia configuración histórica local producto de la relación entre las praxis empresariales y las praxis de los trabajadores (Giniger, 2012). De esta forma, consideramos necesario analizar cómo las empresas especializan las políticas de RSE-PG según sus ámbitos de influencia. Para mostrar muy someramente cuáles son las acciones que llevan adelante las empresas en contextos particulares, tomaremos el caso de la empresa Acindar ArcelorMittal ${ }^{33}$, con el que venimos trabajando.

\section{Especialización situada de las políticas de RSE}

Los reportes de sustentabilidad son los informes que las empresas presentan para dar cuenta de sus acciones relativas a la RSE. En el caso de Acindar ArcelorMittal, este reporte ${ }^{34}$ actúa además como fórmula de adhesión al Pacto Global, en la Red Local. La adhesión al Pacto Global le implica a la empresa configurar su reporte de sustentabilidad bajo los cánones estandarizados del Global Report Initiative (GRI), que permite además de otorgarle un formato común a los reportes, autoevaluar con una grilla y un puntaje, las acciones desplegadas.

Acindar, entonces, organiza su reporte estableciendo cuáles son sus stakeholders o grupos de interés. Los que menciona son: accionistas, clientes, empleados, proveedores, comunidades locales, gobierno, ONGs, organizaciones multisectoriales y de negocio y medios de comunicación. Sin embargo, cuando despliega el contenido de sus acciones, éstas apelan especialmente 1) a los empleados: trabajadores, administrativos, mandos medios y sus sindicatos correspondientes; 2 ) a los estudiantes de escuelas: primarias (a través de la fundación Acindar) y secundarias, particularmente de escuelas técnicas.

El reporte está dividido según los grandes tópicos que organizan la difusión de actividades: la salud y la seguridad, la gestión del trabajo, el medio ambiente, las relaciones con la comunidad y la transparencia en gestión. En cada uno de estos tópicos, Acindar despliega una serie de actividades dirigidas a sus grupos de interés y que conforman los programas que se ponen en juego.

33 Acindar tiene cinco plantas en Argentina. La mayor está ubicada en la ciudad de Villa Constitución, provincia de Santa Fe. La empresa propietaria, ArcelorMittal, realiza operaciones en 22 países y es la principal productora (el 6\% mundial) y vendedora de acero del mundo. En 2012, produjo 88,2 millones de toneladas de acero y obtuvo ganancias por 84 mil millones de dólares, según su propio informe.

34 Tomamos el último reporte publicado, del año 2012, porque para los fines utilizados en este artículo no era necesario desplegar un análisis de todos los reportes que la empresa hizo. 
Respecto del primer tópico, Salud y Seguridad, la empresa lleva adelante ocho programas: "Camino a cero accidentes", "Nada es más esencial que tu salud", "Sistema de gestión integrado", "Política de seguridad para la gestión de contratistas", "Auditoría de estándares de fatalidades", "Seminario de Incentivación Tecnológica - SITEC" y "Comités mixtos de seguridad e higiene ${ }^{\prime 35}$. Como se puede ver, los títulos de los programas refieren especialmente a las políticas dentro del espacio de trabajo y más particularmente a la gestión de la fuerza de trabajo. El sentido de la salud y la seguridad se articula, a través de estos programas, con las metas de la empresa en materia de estándares internacionales de seguridad laboral y con las políticas de control del trabajo. Cada uno de estos programas implica un conocimiento de cada trabajador, a través de análisis y sistemas de diagnóstico médicos, a la vez que se proponen establecer estándares de la organización del trabajo, consensuados bajo los significantes salud y seguridad, que vienen siendo problemáticas y reivindicaciones que los trabajadores, y especialmente, el sindicato metalúrgico local, vienen desplegando como parte de la lucha desde hace más de 40 años. Especialmente, para los trabajadores y el pueblo de Villa Constitución, en donde queda la planta productiva más grande de la empresa, tener políticas de salud y seguridad no pasa desapercibido, ya que en torno a ellas se configuró la lucha histórica sindical (Giniger, en prensa).

Para lo que refiere a la gestión del trabajo, Acindar articula una serie de programas específicos bajo este rótulo. Los programas que aquí despliega la empresa algunos no forman parte estrictamente a lo que se denomina habitualmente como Responsabilidad Social Empresaria, aunque este es uno de los puntos conflictivos de la misma.

La RSE implica unilateralidad, es la acción voluntaria de las empresas, sin tener que negociar, consensuar o discutir con ninguno de sus stakeholders. Sin embargo, en el reporte de Acindar se hace mención a algunos puntos -asumidos como programas de la empresa- que forman parte de las negociaciones colectivas de la misma con los sindicatos. Por ejemplo, "acuerdos salariales" o "reconocimiento de presentismo". Estos tópicos, entre tantos otros, fueron negociados en paritarias y firmados en actas acuerdos. Hacerlos pasar comunicativamente como parte de las políticas impulsadas por la empresa, implica desconocer el origen e invisibilizar la lucha y la negociación de forma explícita. Como venimos postulando, el Pacto Global tiende a ocultar el conflicto y resituar las reivindicaciones en el marco de una estrategia totalizante.

Los otros programas que la empresa publicita en su reporte son los vinculados a lo que se denomina management participativo: evaluación de desempeño, modelo de competencias, comunicación interna y beneficios corporativos.

Por último, bajo el tópico de gestión del trabajo, Acindar promueve el "voluntariado corporativo", que consiste en que los trabajadores donen horas para la realización de "acciones solidarias". Estas iniciativas que la empresa lleva adelante con fundaciones u ONGs (por ejemplo, Fundación Acindar, Techo Argentina y otras) las realiza con trabajo gratuito de sus empleados. No nos vamos a detener en esto, pero es una política signifi-

35 Los comités mixtos de seguridad e higiene a los que se hace mención en el Reporte de Acindar, son los comités de salud y seguridad en el trabajo, que fueron creados por una ley de la provincia de Santa $\mathrm{Fe}$, en el año 2008. Esto ocurrió precisamente después del fallecimiento de dos operarios tercerizados de una planta de Acindar de esa provincia, quemados en el proceso de limpieza de un horno siderúrgico. 
cativa de incorporación y planteamiento de que "todos tiramos para el mismo lado": el bien común nos unifica.

En lo que respecta al rótulo de "Medio Ambiente", Acindar se suma a una iniciativa lanzada oficialmente por Naciones Unidas, que se denomina "Economía verde, ¿te incluye a vos?", y que consiste en una jornada temática que involucra a todos los sectores de la empresa. Además, el resto de los programas que se impulsan son ámbitos de difusión y talleres en escuelas.

Asimismo, Acindar despliega en el reporte la información relativa a los consumos de agua y energía, las emisiones de gases, los residuos, los derrames y la política antiderrames y los gastos e inversiones relativas a la cuestión medioambiental. Esta es una de las políticas de difusión más claramente dirigida desde Naciones Unidas y los protocolos ambientales. Estos protocolos ${ }^{36}$ insisten en la teoría del "capitalismo verde" (Gough, 2013) y promueven que las empresas minimicen los riesgos de polución ambiental y cambio climático. La presentación de reportes de sustentabilidad implica, entonces, dar publicidad a las iniciativas que van en esta dirección.

Respecto al tópico "Relaciones con la Comunidad", la empresa, a través de la Fundación Acindar, muestra en su reporte las acciones relativas a las escuelas. En ellas se interpelan a los estudiantes y a los docentes, estableciendo programas específicos con el contenido definido por la empresa. Estas acciones reenvían a los ejes centrales (trabajo, salud y seguridad, medioambiente, transparencia), por ejemplo, la maratón Acindar (salud), "jugamos seguros" (seguridad), "programa de desarrollo de escuelas técnicas" (trabajo/formación), "el planeta es tu casa, cuidalo" (medio ambiente), etc. Es interesante vincular el profuso despliegue de iniciativas hacia la educación que realiza Acindar (y en general, las empresas en Argentina) con aquello que mencionaba el Ministro de Trabajo, en el evento por los diez años de la Red Local, acerca de la educación como valor histórico nacional. Como efectivamente, Tomada señala, la educación está concebida como factor de transformación y los debates educativos forman parte del sentido común social. Las iniciativas en esta dirección suelen convocar adhesión y consensos.

Por último, el reporte despliega el tópico de "Transparencia en gestión", que refiere directamente al décimo principio del Pacto Global sobre anti-corrupción y plantea un código de conductas, la denuncia de situaciones ilegales dentro de la empresa y publicita la participación en eventos y exposiciones, especialmente como parte de la política de vinculación con otras empresas y corporaciones.

De esta forma, podemos identificar cómo esta empresa despliega una serie de iniciativas que le otorgan carnadura a las políticas de RSE. Los temas abordados y la manera en que son desplegados en los reportes de sustentabilidad, plantean una vocación positiva de la empresa sobre temas acuciantes para los trabajadores y la comunidad. El despliegue de dichos programas e iniciativas está especializado: hay un diagnóstico acerca de quiénes son los sujetos que se pueden y deben interpelar, así como aparece una particular forma de dirigirse a ellos a través de programas. Además, asumir como política propia y voluntaria aquellos acuerdos negociados colectivamente, forma parte de la imagen que la empresa pretende construir de sí misma.

36 Nos referimos aquí a la Cumbre de Río, al Protocolo de Kioto, a los acuerdos de Copenhague y Cancún, y a la plataforma de Durban. 


\section{Conclusiones}

El Pacto Global abarca una serie de políticas de Responsabilidad Social Empresaria, junto con la iniciativa de los Estados miembros de la ONU, que se configura como respuesta a la crisis del capitalismo mundial. La construcción de esta estrategia implicó (e implica) recuperar y resignificar un conjunto de reclamos y reivindicaciones que los sectores populares han desplegado a lo largo de, por lo menos, cuarenta años. Esta resignificación supone resemantizar y por tanto, establecer los límites de aquello que se incorpora a una estrategia sistémica, que pretende relegitimar al capitalismo y reconvertirlo en deseable para el conjunto de la humanidad.

El propósito de configurar una política unificada como mascarón de proa del bloque dominante es claramente relanzar el capitalismo como forma de bienestar común. Para ello, la deshistorización, des-subjetivación y fetichización de las motivaciones populares es central, así como la incorporación de sujetos y organizaciones populares. En este sentido, se desdibuja el origen de los problemas sociales y al mismo tiempo se fragmenta y unifica en un movimiento orgánico: se dividen las reivindicaciones y se las reúne en una doctrina y una política que pretende contenerlo todo. Es por ello mismo, que los capitales individuales -las empresas- se movilizan cómodamente bajo un conjunto de premisas y estándares que les permiten al mismo tiempo, construir una imagen socialmente comprometida en sus lugares de emplazamiento y desplegar sus negocios en el mercado mundial.

Las formas en las cuales se despliega la política del Pacto Global se realiza de manera especializada en los contextos espacio-temporales específicos en los que los actores llevan adelante sus acciones. Estas especializaciones implican tomar en cuenta las historias particulares y las tensiones y conflictos propios de los lugares de emplazamiento, reenviando en un movimiento dialéctico lo general con lo particular.

Sin embargo, las pretensiones totalizadoras del capital en su estrategia de Pacto Global hacen eclosión con la realidad concreta, la crisis se hace carne en los trabajadores y produce mayor desigualdad y pobreza en la mayor parte del mundo.

Las resignificaciones y las resemantizaciones no son patrimonio del capital, aún cuando el proyecto orgánico se despliegue más eficazmente. Los sectores populares también recuperan estos consensos y los reutilizan y resemantizan, con grados diversos de distanciamiento y adhesión con las iniciativas y proyectos del poder. En todo caso, la tarea de convertir las aspiraciones populares en proyecto orgánico aún es materia pendiente, recuperando terreno y asumiendo la iniciativa.

\section{Bibliografía citada}

Borón, Atilio (2009) De la guerra infinita a la crisis infinita. En: XI Encuentro Internacional de Economistas sobre Globalización y Problemas del Desarrollo, La Habana, Cuba 2-6 de marzo de 2009.

http://www.formacion.psuv.org.ve/wp-content/uploads/2013/06/De-laguerra-infinita-a-la-crisis-infinita.pdf

Delgado, Eric (2007) La Responsabilidad Social Empresaria y los valores cooperativos. Dos cuestiones distintas. Realidad Económica, № 230, Buenos Aires, Instituto Argentino para el Desarrollo Económico, páginas 47-60. 
Figari y Giniger (2014) Responsabilidad Social Empresaria y Pacto Global: Bases para la reflexión conceptual. Revista Latinoamericana de Estudios del Trabajo, № 31, Año 19, páginas 41-70, Brasil

Giniger (en prensa) Así se templó el acero. Estrategias de control laboral y respuestas sindicales en el emplazamiento sidero metalúrgico de Villa Constitución. Implicancias dentro y fuera de la fábrica. Buenos Aires, Ediciones Luxemburg

(2014) Doctrina Social de la Iglesia y Responsabilidad Social Empresaria: ética y política del neoliberalismo. Revista Sociedad y Religión, № 42, Octubre, páginas 1-29, Buenos Aires.

Gough, Ian (2013) Climate change, social policy, and global governance, Journal of International and Comparative Social Policy, pp. 185-203, UK.

Gramsci, Antonio (1992) Antología. Selección, traducción y notas de Manuel Sacristán. México, Ed. Siglo XXI.

Harvey, David (2007) Breve historia del neoliberalismo. Madrid, Akal

Regalado, Roberto (2008) Encuentros y desencuentros de la izquierda latinoamericana. Una mirada desde el Foro de Sao Pablo. México, Ocean Sur

Teszkiewicz, Winter, Wanschelbaum, Reboursin, Giniger (2012) Los balances de Acindar: lucha, represión y concentración económica en los 70. Comunicación en: Jornadas de Historia Social Regional. Instituto Superior de Profesorado № 3 “Eduardo Lafferriere" de Villa Constitución, Santa Fe.

Vidal, María del Mar (2015) La dimensión internacional de la Responsabilidad Social Empresaria, España, Editorial Bomarzo

Wanschelbaum, C. (2014) La educación durante el gobierno de Raúl Alfonsín (Argentina, 19831989). Revista Ciencia, Docencia y Tecnología, Vol. XXV, №48. Argentina, páginas 75-112.

\section{Fuentes secundarias citadas}

Acindar ArcelorMittal (2012) Reporte de Sustentabilidad. Argentina. En: http://www.acindar.com.ar/es

Ban Ki-moon (2009) El Pacto Mundial y la creación de mercados sostenibles. Foro Económico Mundial Davos (Suiza), 29 de enero de 2009. En: https://www.unglobalcompact.org/NewsAndEvents/news_archives/index.html

Centro regional de apoyo para América Latina y el Caribe. http://www.centroregionalpmal.org/web-pacto/esp/index.php

Desgrabaciones de las intervenciones en el evento: "Décimo Aniversario de la Red Argentina del Pacto Global". Grabaciones tomadas en el trabajo de campo, 3 y 4 de noviembre de 2014, donde hablaron, entre otros, Willi, Chávez, De Bueno, Rodríguez, Ávila, Prock, Videla y Tomada.

Folleto Red Argentina del Pacto Global de Naciones Unidas (s/f) 10 Aniversario. Argentina.

Foro de San Pablo (1993) Declaración Final de La Habana. Cuba. En: 
http://forodesaopaulo.org/declaraciones_finales/declaracion-final-declaracaofinal-la-habana-1993/

Global Reporting Initiative (s/f). G4 Sustainability Reporting Guidelines. En: https://www.globalreporting.org/reporting/g4/Pages/default.aspx

Kofi Annan (1999) Proposes Global Compact. Foro Económico Mundial Davos (Suiza), 31 de enero de 1999. En:

https://www.unglobalcompact.org/NewsAndEvents/news_archives/index.htm I (traducción propia)

Ministerio de Trabajo, Empleo y Seguridad Social (2009) RSE y Trabajo Decente en la Argentina. Buenos Aires. En:

www.trabajo.gov.ar/downloads/.../red_rse_y_trabajo_decente.pdf

Naciones Unidas (1995) Informe de la cumbre mundial sobre desarrollo social. Copenhague, 6 a 12 de marzo de 1995. En:

www.cinu.org.mx/temas/desarrollo/dessocial/cumbre/copenhage.htm

Pacto Global (s/f) Comunicaciones de Progreso. En:

https://www.unglobalcompact.org/COP/index.html

Pacto Global (s/f) Diez Principios. En:

https://www.unglobalcompact.org/AboutTheGC/TheTenPrinciples/index.html 